\title{
7. Indigenous entrepreneurialism and mining land use agreements
}

\section{Sarah Holcombe}

\section{Introduction}

In the Pilbara region of Western Australia, the focus of this chapter, the mining boom - or the 'ramp up' in production as it is referred to within the industry - is such that negotiations for land access have intensified and annual payments to the Indigenous organisations examined here have increased threefold since 1997. These organisations are the Gumala Aboriginal Corporation (Gumala) and Gumala Investments Pty Ltd (GIPL); set up to manage the Yandicoogina Agreement (YLUA). This chapter critically examines the mechanisms through which Indigenous beneficiaries are able to articulate to a Land Use Agreement (LUA) as individuals, with specific attention to possibilities for entrepreneurial activity. The range of possibilities for direct and tangible benefits from agreements is a key area of Indigenous concern. Because of the complexity of the land use agreements examined for this project, this chapter will only focus on Rio Tinto's YLUA in the Hamersley Ranges of the Pilbara. Indigenous 'beneficiaries' operate in a politically volatile and economically expansive context in this area of engagement with the mining sector and the organisations developed to manage the agreements. ${ }^{1}$

To closely consider a range of articulations with the YLUA, it seems apposite to provide a series of examples of the ways in which particular individuals have engaged with opportunities and, conversely, individual critiques of structural limitations on engagement within the YLUA. To some extent, these examples will be biographical. Indeed, a few Indigenous people in the Hamersley region have published biographies, several with the assistance of Rio Tinto and organisations established to manage agreements. One of the biographical 'case studies' discussed in this chapter will be that of Lola Young (2007). The other individuals discussed will, for ethical reasons and to retain anonymity, be referred

\footnotetext{
${ }^{1}$ I would like to thank members of Gumala based in Tom Price and the surrounding homelands, and those members residing in Port Hedland, Wickham, Roeburne and Karratha who spent time speaking with me for this project during 2003 and 2004; with special thanks to Darren Inji, and Slim Parker. Thanks also to staff in the Tom Price Gumala office, especially Bill Day (during that time and more recently) and Larry Softley, who supported this project during field research. Thanks also to Mark Simpson and staff of Rio Tinto's Aboriginal Training and Liaison Unit in Dampier. More recently, discussions have been held with Gumala project officer Don Gordon and the new Gumala Chief Executive Officer Steve Mav, who have been keen to articulate the new generation Gumala that this paper has only begun to grapple with. The views expressed in this paper are not necessarily those of Gumala staff. Finally, I contacted all four of the case study individuals in this chapter, providing drafts to them and best efforts have been made to encourage all of them to vet their stories.
} 
to by pseudonyms. These brief accounts of individual engagements with the industry are included towards the end of the chapter, after consideration of the context within which individuals are enabled to operate. While entrepreneurialism is a focus of this research, it encompasses the ways in which individual beneficiaries to the Agreement can benefit, rather than solely examining possibilities for developing business enterprise.

\section{Fig 7.1 The Pilbara region, Western Australia}

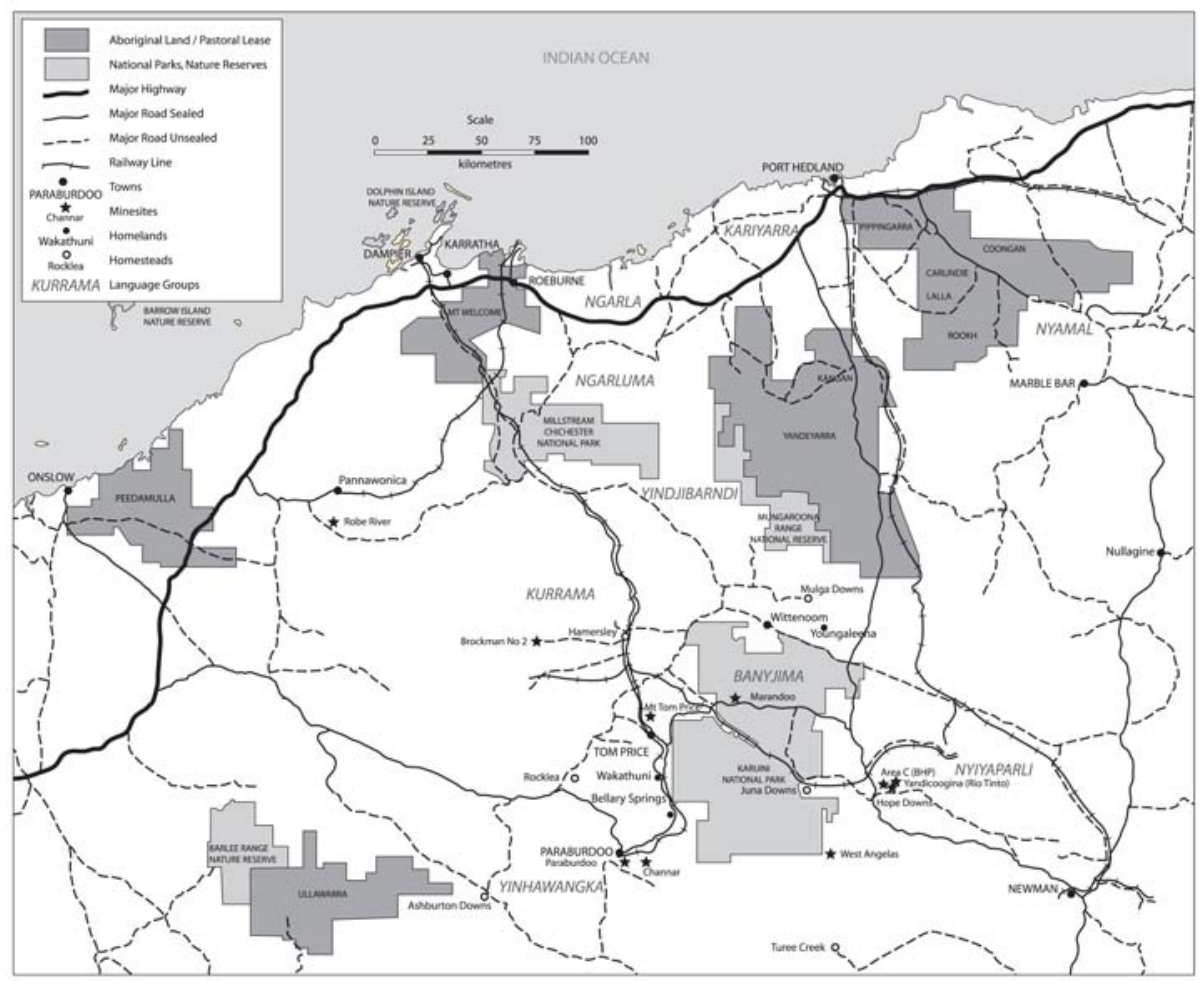

Source: Cartographic Services, Research School of Pacific and Asian Studies, ANU.

There are a range of structures and mechanisms through which Indigenous 'beneficiaries' to the YLUA can engage with its financial benefits. Many of these benefits are indirect or process oriented - ranging from gaining sitting fees from committee membership and, presumably, having some element of investment over allocation of resources, to working on heritage clearances for the Company. While this analysis is concerned with the YLUA, and relevant elements of the Agreement structures will be outlined below, the broader economy of the region is such that individuals may be party to more than one agreement with different mining companies. Indeed, some individuals sit on such a range of committees that their attendance at meetings is a full time occupation. Other more direct and secure means for financially engaging with the YLUA include employment 
for organisations that were established to manage it; elderly and infirm people gaining regular 'top-up' monies from the Foundation (no longer operating), to being employed on the mine site (though this is open to anyone Indigenous, non-Indigenous, local or global) and in associated operations; working on specific cross-cultural programs provided to non-Indigenous mine staff; and self-employment in small mine-related contracting businesses.

\section{An Indigenous entrepreneurialism}

The use of the term 'entrepreneurialism' is informed by Indigenous Canadian experience where social sustainability and the recognition of political rights has been a more evident outcome of entrepreneurial activity than economic sustainability (Peredo et al. 2004). This alternative understanding of entrepreneurialism is useful in analysing the motivations of many Indigenous Australians' attempts at entrepreneurial activity through the land use agreements under consideration here. Non-market driven modes of entrepreneurialism also need to be canvassed. Recent research in Australia by Hindle and Lansdowne (2005), that attempts to draw together Australian and American Indian perspectives on Australian Indigenous entrepreneurialism, also suggests that entrepreneurship here should be understood as encompassing more than economic imperatives. They define Australian Indigenous entrepreneurship as: the creation, management and development of new ventures by Aboriginal people for the benefit of Aboriginal people. The desired and achieved benefits of venturing can range from the narrow view of economic profit for a single individual to the broad view of multiple, social and economic advantages to entire communities... (Hindle and Lansdowne 2005: 132). ${ }^{2}$

In light of this it is appropriate to reconsider notions of success or failure and indeed the criteria under which 'business' applications are considered-for instance, within the framework of agreements. Certainly this lack of support for developing individual and family businesses was raised as a significant issue for Indigenous beneficiaries of the YLUA in the Review of the associated Gumala Investments Pty Ltd and the Trusts (Hoffmeister 2002). Foley, another researcher in this area in Australia, also found that the definition of success for Indigenous Australian entrepreneurs is 'based on subjective notions derived from the entrepreneurs themselves, and is not solely restricted to financial criteria' (Foley 2006: 1, see also 2003).

\footnotetext{
2 I am cautious in using this research, however, as it seems to have focused on developing an erratic and confusing method utilising a number of 'theories' whereby a 'formal paradigm' is sought to determine whether entrepreneurial business ventures can claim to be Aboriginal or not. Amongst other issues the claim for 'global relevance' is peculiar as the interviews were restricted to Australia and the United States. No examples of Aboriginal enterprise are canvassed and nor it seemed were Aboriginal enterprise operators spoken with.
} 
Foley focuses on Indigenous entrepreneurs who are the owners and managers of stand-alone commercial enterprises in urban environments because they comprise the majority of Indigenous entrepreneurs in Australia. Although Foley focuses on mainstream commercial success, importantly he problematises the tension within Indigenous policy between community development and the development of the individual (2006: 5). He notes that there is little recognition of the socioeconomic category of the individual Indigenous entrepreneur and that policy funding structures have a blanket approach toward Indigenous 'communities' (Foley 2006: 5-6). ${ }^{3}$ Indeed, this issue of the way in which the Indigenous 'community' - as an encompassing category within the YLUA - is embedded in the 'community development' discourse was discussed at length in a previous paper (Holcombe 2006). It is important, nonetheless, to observe this issue again as a restrictive and limiting factor that discourages entrepreneurialism.

There are legal limitations on the Trusts set up under the YLUA and the 'community benefit package' (as the agreement is also referred to) as they impose both corporate expectation and constraint on Indigenous action. This chapter proposes that major resource companies incorporate strategies in land use agreements that enable individual Indigenous people, who are party to agreements, to develop the capability to deal with the potential opportunities that these agreements present. At the same time it proposes a broader definition of 'opportunity'. A central contention is that mobilising individual agency to strengthen capacity to be socially productive may not necessarily lead to mainstream economic productivity, but rather to producing community and family economies. Such local informal economies tend to be marginalised by the dominance of large scale resource development and the focus on mainstream employment in the industry and in government policy (see Holcombe 2006).

How is this active engagement facilitated or hampered by the structures set up to disburse the benefits? Such structures are not neutral frameworks that allow an innocent expression of Indigenous interaction. They are deeply informed by a development discourse and are themselves a major arena of development in remote areas; these structures need to be understood in those terms. According to the United Nations, the fundamental purpose of development is '...to enlarge people's choices. In principle, these choices can be infinite and can change over time... People often value achievements that do not show up at all, or not immediately, in income or growth figures...' (Haq n.d.).

\footnotetext{
3 Foley focuses on an urban/remote divide: typifying and contrasting urban individuals as against remote communities. However, he tends to use the concept 'community' un-problematically as assumed places of shared interests. I would argue that 'communities' can't be assumed in remote areas either. There is a considerable literature critiquing the community concept, see especially Gusfield (1975) and Cohen (1985) and for (Central) Australia, Holcombe (2004b).
} 
It seems important to recall the fact that, in the Pilbara for instance, only 30 per cent of Indigenous adults participate in the mainstream labor market and, of these, 22 per cent work in the mining industry (Taylor and Scambary 2005: 28-37). These findings suggest that focusing on alternatives may be a pragmatic way to think more broadly about the scope of the YLUA and what it can realistically deliver. Likewise, the encouragement of diverse alternative economies would also seem to be critical to any post-mine life in these remote regions and encouraging entrepreneurs is an element of planning for this future. As human geographers such as Gibson-Graham (2002) and Howitt (2001) have found, alternative economies encompass heterogeneity and run counter to the notion that there is a homogenous community of interests that is served by a uniform capitalist economy (see also Community Economies Collective 2001). Certainly, the manner in which the term 'community' is embedded in the YLUA presumes a unified and shared set of communal Indigenous interests - and consequently the diversity of these interests becomes submerged (see Altman, Chapter 2; Scambary, Chapter 8).

This research is informed by the human development approach pioneered by economist Amartya Sen (Sen and Anand 1994; Sen 1999) and further refined by normative philosopher Martha Nussbaum (2001). This approach has been used as a conceptual framework by the United Nations Development Program since 1990 'to inform policy choices in many areas, from poverty reduction to sustainable development to gender to globalisation to governance' (Fukuda-Parr, Lopes and Malik 2002: 1). Research by the World Institute for Development Economics, especially by Sen (Sen and Anand 1994; Sen 1999) and Nussbaum (2001), has found that the principle of 'each person as an end' needs to be the fundamental basis for 'development planning'. In this human rights based approach to agreements as development, instead of asking questions about people's satisfactions (which are subjective and may be conditioned), the questions are about what they are actually able to do or to be, as it is in this space that social equality and inequality are best raised (Nussbaum 2001: 12). For instance, the dominant approach to assessing quality of life previously focused on Gross National Product (GNP) per capita, 'treating the maximisation of this figure as the most appropriate social goal and basis for cross-cultural comparison'. However, such assessment has to investigate the distribution of this wealth and income; as encapsulated in 'who has got the money and is any of it mine?' (Nussbaum 2001: 60).

This approach to issues of the distribution of wealth and benefits invites examination of the way the $\$ 60$ million plus benefit package of the YLUA affects individuals: where and how does this money get distributed and can 'beneficiaries' say any of it is theirs or that they had a role in deciding how it was spent or invested? The question that this then begs is whether the organisations set up under the YLUA are creating an enabling environment for 
the Indigenous stakeholders they are purported to benefit; are they encouraged to be agents?

Weighing up immediate tangible benefit - requests of cash or seed money for a family or individual enterprise - against long term or nascent benefit is a complex balancing act and there are not any simple solutions, or none that are directly transferable across different regions. Nevertheless, this is a tension that has been found to exist in relation to other agreements and patterns have formed around this difficult balance (see Altman, Chapter 2). In the YLUA the balance is heavily weighted in favor of long term future investment and financial risk minimisation, and does not give enough credit to potential or immediate entrepreneurial possibilities or investment in promoting these opportunities. Indeed, this was the major thrust of the findings of the Review of the Trusts and GIPL (Hoffmeister 2002). As will be discussed, however, in the six years since this Review there has been a shift toward diversification and small scale business development. As Gumala - one of the two key organisations set up to manage the agreement - has noted, they are an organisation in the process of transforming themselves.

According to the YLUA not less than 40 per cent of the available income should be invested and not less than 30 per cent spent on education and training, and business development. In fact it was found that most of the available income was invested, approximately 40 per cent more than targeted (Hoffmeister 2002): ${ }^{4}$ as of June 2007 there was approximately \$40 million being held by GIPL (Bill Day, pers. comm. June 2007). This business philosophy weighted toward long term investment may be, in part, a risk aversion strategy. ${ }^{5}$

However, this approach to investment can limit the potential of the money to build human capital, or, as the first non-Indigenous Director of Gumala Enterprises (GEPL) (and Graham (Polly) Farmer Foundation Chief Executive Officer (CEO)) noted, 'if the money is not being spent it's not doing good' (pers. comm. 2004). ${ }^{6}$ Aristotle's prescient observation seems pertinent here, 'wealth is evidently not the good we are seeking; for it is merely useful and for the sake of something else' (Aristotle $350 \mathrm{BC}$ ). The 'something else' may be understood through the concept of fungibility, recently bought to prominence in Australia by Noel Pearson (Pearson and Kostadikas-Lianos 2004; see also Bourdieu 1986; Coleman 1988) - being the transaction or transformation of one form of capital

\footnotetext{
4 The figures referred to here from the 2002 Review are: $\$ 4.7$ million were spent on investments to $\$ 1.4$ million on education, training and business development.

5 Another reason for the increased long term investment, to be examined below, was that insufficient proposals for business enterprises were put forward in the first five years. As the Review makes clear, this is indicative both of the lack of support for developing such proposals and the perceived (and actual) constraints on what constitutes an acceptable proposal.

6 The Graham (Polly) Farmer Foundation is a philanthropic organisation that provides after school mentoring and homework facilities for Aboriginal high school students in towns in the Pilbara region and other supportive roles. Rio Tinto is also a partner through their Futures Fund.
} 
into another. ${ }^{7}$ In this case a more significant proportion of the financial capital from the YLUA could be available to be transformed into human, social and cultural capital. ${ }^{8}$ Moving beyond the focus on the agreement as primarily an economic asset is a step toward this approach.

It seems that this is the approach being increasingly adopted by Gumala, as is possible within the confines of the YLUA. Gumala grappled with the findings of not only the first five-year Review (Hoffmeister 2002), but now the second Review which was finalised in August 2008.

\section{Gumala Aboriginal Corporation, the Trust and Business arms}

'Gumala' is an Aboriginal word in the Bunjima Language meaning 'all together'. This ideology was important in binding three language groups-Bunjima, Innawonga and Niaparli (who maintain native title in the region of the Yandi mine and associated infrastructure) - together in the YLUA. ${ }^{9}$ However, holding them together has been a major challenge with ongoing tension between elements of each group, not least because there now are over 750 Aboriginal beneficiaries, party to the YLUA. Some of these tensions, recent and historical, will be discussed below.

There are four bodies that operate under the YLUA: Gumala Aboriginal Corporation based in Tom Price, its business arm GEPL, the Gumala General Foundation, and Gumala Investments Pty Ltd (GIPL). GIPL was established to act as the Trustee of the General Foundation, which receives payments of between $\$ 2$ million and \$5 million per annum from the YLUA. ${ }^{10}$ Importantly, the Trustee is independent of Gumala and has ultimate decision-making powers in all matters relating to the Foundation. A Foundation for the elderly and infirm was

\footnotetext{
7 Pearson and Kostakidis-Lianos (2004) argue that Aboriginal land-holding structures and property rights, such as native title, are not readily fungible into economic assets. In fact they state that land rights are 'dead capital' because they cannot be leveraged to create capital. They give the example of setting up a private enterprise on Aboriginal Land as a 'virtual impossibility' (Pearson and Kostakidis-Lianos 2004: 2). However, it must be pointed out here that the agreements under consideration in this paper were negotiated under the Native Title Act 1993 - hence leverage was gained through Aboriginal property rights and the outcome is an agreement. Such an agreement is a very significant economic asset. Likewise, under the Aboriginal Land Rights (Northern Territory) Act 1976, the right of consent provisions also provide significant economic leverage.

8 There is a vast literature on the concept of social capital with the World Bank, in particular, bringing the concept into prominence with their interest in understanding the local impediments to development in considering the social as opposed to the economic face of adjustment (Woolcock and Narayan 2000). Critiques of the concept (Fine 2003; Hunter 2004; Renzio 2000; also Woolcock 1998 before joining the World Bank) have noted that there is a marked neglect in how social capital is actually created, that it is a catch all category designed to capture any asset that does not fall under the conventional categories natural, physical and human. These authors also focus on the definitional chaos of the concept.

9 The orthography used here for these language groups follows the Gumala spellings. Note, however, that there are a range of alternatives. The orthography preferred by the Wangka Maya Pilbara Aboriginal language centre based in Port Hedland is as follows: Banyjima, Yinhawangka and Nyiyaparli.

10 This annual amount is currently closer to \$5.5 million (Darren Inji, pers. comm. June 2008).
} 
established to provide benefits to those so defined for the first five years. It no longer operates. Apart from managing and maintaining the capital base of the General Foundation, GIPL considers project funding requests from Gumala. Gumala is charged with consulting members of the beneficiary group, and developing, researching and preparing proposals for investments and community projects, as the on the ground Indigenous organisation. Gumala is thus the manager of GIPL and the sole shareholder of GIPL as Trustee. GIPL comprises six directors, three directors who are independent and three directors who are traditional owners as representatives from the three language groups.

Many of the issues in the following discussion are drawn from the 2002 Review of the Trusts (also known as Foundations) and GIPL, along with interviews conducted over 2003-04, with members of Gumala across the Pilbara and, more recently, telephone interviews with some of these same people. Although the Review was not of Gumala or its business arm GEPL, a number of the Review findings directly engage with issues associated with their operations. Many of the issues of concern raised in the 2002 Review remain pertinent, although a number of the recommendations have been acted upon. There are several apparent reasons for the continuing relevance of the 2002 Review findings. One of these was described as the lack of communication between the two key bodies - Gumala and GIPL-and between these bodies and their members. Indeed, in early to mid 2007 Gumala attempted to liquidate GIPL to, as one commentator noted, 'get their hands on the booty' (Bill Day, pers. comm. May 2007). At June 2007 this 'booty' was worth approximately $\$ 20$ million (Siopsis J 2007). GIPL Trustees and other supporters applied for and won an injunction against their liquidation and, to avoid protracted legal costs, a mediated settlement was reached. This issue, to be discussed further below, is raised here to situate some of the tensions between these organisations and to place at the forefront this issue of the contested access to the benefit stream.

The Review found that most available income was invested and that considerably less was spent on program areas, especially education, training and business development. ${ }^{11}$ While at that time GIPL and the Gumala CEO stated that there had not been enough proposals, members said that they found it hard to put proposals forward and to understand the approval process. It seems that the most 'business ready' and 'job ready' tended to be most advantaged and the approach continues to be that business proposals must have a prospect of making a profit. Gumala business development funding had done little for groups who were not previously business ready. A key recommendation was to establish a

\footnotetext{
11 Indeed, the tensions inherent in this pattern of investment and expenditure; getting the balance right, have a long history. These issues are not unique to this Agreement, but rather were apparent in the earliest royalty associations and trusts set up to disburse mining monies in the Northern Territory (see Altman 1983). What is perhaps different here is both the scale of the Agreement and the Indigenous expectation.
} 
business development assistance scheme within 12 months of the Review to be situated within Gumala (Hoffmeister 2002). A Business Development Officer was employed for a short period, but at that stage it was not successful and was discontinued. A Business Loans Guarantee Program has also been operating, but with little success. In late 2008, the Business Loans Guarantee Program was in the process of being transferred from GIPL to Gumala in order to facilitate greater utilisation. Since the first Review, members' businesses which have been supported include a cattle station, an earthmoving enterprise, a cultural awareness business, a fabric and garment design enterprise and a bush products enterprise (see Lola Young's case study below).

Exactly what sort of 'business development' was to be supported was found to be a major area of uncertainty and dissatisfaction for Gumala members interviewed for the Review. The Gumala newsletter at that time highlighted that, 'All funds from the General Foundation must go towards community development projects and NOT INDIVIDUALS' and further that, 'All language groups are encouraged to submit proposals, as outlined in their community action plans' (Gumala News, December 2001, capitals in original). Without having the benefit of sighting any 'community action plans', it seems that members would be justified in their confusion about what constitutes a successful proposal. It was noted that individual and family business development proposals were rejected when they were put forward. In the 2002 Review the Trustee indicated that a cautious approach was taken in only supporting projects with a high probability of success. Such projects were expected to have a 'community benefit'. This raises the question of how benefits to individuals and families are distinguished from broader community benefits. This distinction would be especially blurry where these individuals and families are living on homelands - that is, small communities. At least two family/individual business have been supported.

In interviews held with Gumala members, the issue of not funding individual or family enterprise was seen as not only extremely limiting, but as a potential liability. Interviewees' understanding was, that an entrepreneurial individual could only be allowed to work with others in the local homeland who may or may not be interested in the project, despite others, such as non-Indigenous people, being able to input greater skills. A general comment was that an entrepreneurial individual did not want to have to rely solely on their family or those in the local homeland for success. This is consistent with Gumala members noting in the 2002 Review, that supporting individuals in small business is a key to securing economic independence. Likewise, it is arguable that encouraging such individuals as role models may have wider ramifications. This is the approach adopted by the United Nations Development Program, discussed earlier, and accepted internationally as a means of growing employment possibilities within a community. 
Cash payments to beneficiaries cannot be granted under the Trust structures. This is for some, who are critical of this approach, as much a political and rights issue: believing that they have a right to manage their own finances, cash payments or otherwise, like other Australians. Many of the Gumala members interviewed found the lack of choice patronising, and there was little understanding that the charitable status of the Trusts was a reason for not granting such payments. Gumala members were well aware that the neighboring IBN (Innawonga, Banyjima, and Niapali) Agreement with BHP Billiton, also of comparative scope and majority overlapping membership, does provide limited annual cash payments to members. If membership of Gumala is viewed as part of a mosaic of LUAs in the region, this feature of the IBN Agreement could be understood as assuaging, to some extent, the call by those individuals who are members of both. ${ }^{12}$

The 'community development' that is occurring is homeland (outstation) infrastructure development and support for associated cultural activities. Six homelands in particular, located mainly in the mine hinterland, are the recipients of these monies. Projects supported include roadworks, tractors and sheds, medical rooms, a community bus and a breakfast and homework centre, and one homeland received funding for essential services. This activity-supporting small dispersed settlements on land where particular families have rights by customary law - seems to be almost universally regarded as adding value to people's lives and was widely discussed by Gumala members as positive. The 'priorities for the future' listed as part of the 2002 Review noted an emphasis on returning to country with the assistance of community development projects and the preservation of law and culture; but also included business development loans for individuals. Accordingly, community development was not understood by Gumala members as excluding small scale business development.

There is the risk that the money being spent by Gumala on essential services could have been spent instead on fostering small scale business. As O'Faircheallaigh (2004a: 43) suggests, 'If mining payments are used to pay for basic social services [that are citizenship rights] then opportunity'... to utilise a significant economic asset cannot be utilised to overcome economic disadvantage. A case can be made that the development of these homelands has been an example of 'substitution funding', whereby the expenditure from mining

\footnotetext{
12 Calls by many Gumala members for individual entitlements in the form of cash payments can also be considered as another form of entrepreneurialism, taking into account that a fundamental feature of entrepreneurialism is an individual, as opposed to a collective, approach to engaging in financial opportunities. Nevertheless, I acknowledge that such compensatory or cash payments may be regarded as passive, whereas entrepreneurial activity is necessarily active. However, for my purposes here, the immediate expenditure issue needs to be understood in light of the framework of constraint that the YLUA places on individual capacity to choose, as both a political and social right. Therefore, it can be considered as falling under the Aboriginal Canadian definition of entrepreneurialism (Peredo et al. 2004), as a broader definition than that offered by Hindle and Lansdowne (2005) and Foley (2006).
} 
payments has substituted for government funds that were spent elsewhere. The result is no net increase in spending on services in these communities (see O'Faircheallaigh 2004a: 43). This issue of 'substitution funding', potentially jeopardising access to commonwealth or state-funded programs because of mining agreement monies, is not a new one. Pre-native title, this risk was most notable where significant financial benefits were negotiated in the context of land rights legislation in remote areas (see Altman 1983: 112, 1985a). Gumala was also not unaware of this risk and in 2004 the then CEO and Senior Project Officer both spoke of the value of projects that leveraged government resources. Such projects included the medical rooms at one homeland that were built by YLUA funds, as the government would not provide capital infrastructure funds, but would provide recurrent resources for staffing; and the homework centre at a homeland where the infrastructure was supplied by Gumala, but the computers and network were subsidised by the federal government 'networking the nation' program. The risk of substitution funding remains significant and requires ongoing strategic management (see Altman, Chapter 2; Levitus, Chapter 4). In view of this, Gumala and GEPL employed a Grants Officer in August 2008 to ensure that they leverage grant money and sourced available opportunities.

As suggested by the discussion above, the 2002 Review found general dissatisfaction about the Trustee and the GIPL manager handling funds for education, training, and business development. A number of the criticisms to emerge from the 2002 Review revolved around the perception that GIPL was constraining opportunities for accessing the YLUA monies. Members were concerned that the Trustees were too far away, several resided in Perth, and knew little of their concerns and needs. In an earlier paper I have indicated that some Gumala members perceived that they have insufficient control over how the money in the Trust is distributed' (Holcombe 2004a: 9-10). Part of the reason for this is the decision-making structure of GIPL. There are three non-Indigenous and three Indigenous representatives (one from each language group) on the Board of Trustees, on three-year terms and meeting twice annually. In 2004, however, they were only having one face-to-face annual general meeting, to save costs. This sense of disconnection from the decision-making process may be inevitable, however lack of transparency in the decision-making process and slowness of decision-making were cited as significant in the 2002 Review.

The 2002 Review found a need for more cooperation between the Boards of GIPL and GEPL (as the Gumala Enterprise arm), and for better information dissemination, communication and consultation by the GIPL Manager and Trustee with Gumala members and Gumala officers. The issue of GIPL having ultimate decision making power over Trust funds while Gumala as manager could only pass on funding proposals, did not sit well with some Gumala members and especially the then CEO. This tension between Gumala and GIPL came to a head in 2007 when Gumala attempted to sack the GIPL Trustees and appoint a 
liquidator who would enable compliant trustees to then transfer the remaining $\$ 40$ million investment fund to Gumala. For its part, GIPL maintained that it had concerns related to the manner in which financial controls were exercised and the lack of proposals being put forward by Gumala (Siopsis J 2007). GIPL lodged an injunction against its liquidation on the basis that there had not been a full vote of members and Gumala (as manager of the Trust) had breached its fiduciary duties to the beneficiaries in its lack of openness. The court ordered a mediated settlement and shortly thereafter the Gumala CEO, who had held the position for approximately five years, resigned. A new CEO was appointed in January 2008 and a restructured Gumala committee was established. ${ }^{13}$

Finally, a number of the 2002 Review recommendations have been acted upon. For instance, the Review recommended that children of Gumala members be supported through the provision of scholarships for secondary school, higher education, and for post-school vocational training. A number of children now attend Perth secondary schools on scholarships. In 2006, the business arm of Gumala, GEPL, invested in the Karijini Eco Retreat tourism venture, where there are currently 10 local Indigenous people employed over a nine month tourist season. This approach to business development acknowledges that diversification beyond the mining industry is a strategy to distribute risk.

In early $2008,{ }^{14}$ with a new Governing Committee and a new Chief Executive, Gumala made major changes in its structure by increasing numbers of staff, creating an integrated relationship with GEPL, and implementing fundamental changes in relation to business development. These include the expansion of existing corporate businesses and the development of others, such as a major accommodation project in Paraburdoo for Rio Tinto staff, contractors and tourists and a proposal for a large business complex in the centre of Tom Price with shops, offices, training facilities, accommodation and new corporate head quarters for Gumala. A new strategic plan is also being developed so that GEPL can seize upon the opportunities created with the Pilbara mining boom.

To cater for individual circumstances a Members' Support Unit has also recently been established with extra staff to deliver direct benefits through various programs. These include sport and recreation, financial support for funerals and headstones, emergency assistance, a pensioner program, critically ill patient support, health and wellbeing programs, dental and ancillary health, computers

\footnotetext{
13 This committee restructure was also partly due to an Australia-wide Office of the Registrar of Indigenous Corporations development that reduced the size of committees for Aboriginal corporations by half. Gumala had previously required 18 elected members, six from each language group. Now the requirements are three members of each language group, giving a maximum of nine. Although smaller boards/committee may be more efficient and cost effective, this may be at the expense of transparency, and real and perceived exclusivity.

14 The detail in this paragraph and the following paragraph was provided by Gumala (D. Gordon, pers. comm. 10 October 2008).
} 
for students, a scholarship scheme (discussed earlier), and home loans. Seven trainees have been employed at the Gumala office, while GEPL is also expanding its Indigenous workforce.

\section{Individual Indigenous engagement}

To illustrate something of the diversity of Indigenous engagement with mining interests, biographical details of several individuals are discussed below. This material covers not only consideration of some small and large scale business activity, but also process-oriented engagement that speaks to a political and cultural agenda, rather than solely financial motivation.

\section{Case 1: PN}

$\mathrm{PN}$ is an articulate young to middle aged Niaparli woman who resides on her family outstation in the Hamersley Ranges. In 2004 she was community President. At that time she was a member of seven committees, boards and working groups, including Gumala, GEPL, the Pilbara Native Title Service (PNTS) Regional Committee, the Yamatji Marlpa Barna Baba Maaja Aboriginal Corporation (YMBBMAC) Governing Committee, ${ }^{15}$ the Niaparli (native title) working group, and the Rio Tinto Central Negotiating Committee. ${ }^{16}$ Her membership of these organisations, involves a strong element of 'keeping a finger on the pulse' of the regional socioeconomic politics. In a 2005 PNTS press release, PN spoke strongly about Rio Tinto's need to maintain standards of corporate social responsibility and to negotiate retrospectively, given the expansion of mines that were developed prior to the Native Title Act 1993 without traditional owner approval. ${ }^{17}$ The level of commitment to monitoring the massive industry presence is apparent.

At the time of interviewing $\mathrm{PN}$ and compiling the above membership list, it seemed one, extreme, end of a spectrum of engagement - the pointy end of the process side of the mining boom. However, this type of engagement seems to suit many Indigenous people and is not necessarily uncommon. What is perhaps striking about PN's membership commitments is the level of activity. While some individuals feel a clear need to engage politically with such a powerful industry group, there is a flexibility to attending meetings which caters to other

\footnotetext{
15 This governing committee oversights the policy direction of the YMBBMAC. This is the organisation that acts as the native title representative body for the Pilbara region, as well as the coastal region around Geraldton to the south west. It incorporates the Yamatji Land and Sea Council and the PNTS.

16 The Central Negotiating Committee was formed in 2003 to engage collectively with Rio Tinto Iron Ore (RTIO) in developing a regional framework through which to negotiate a coordinated approach to the ongoing expansion of the industry and the new and evolving agreements. In 2006, the Central Negotiating Committee developed into a private company owned and controlled by 10 Pilbara traditional owner (language) groups. With an office in Roebourne, chaired by Slim Parker, the Marnda Mia Central Negotiating Committee 'aims to build coordinated, institutionalised capacity for local Indigenous families and groups and provide a strong local voice' (see Rio Tinto media release, 26 September 2007).

17 'Pilbara Aboriginal meeting condemns Rio Tinto', PNTS media release, 31 May 2005.
} 
Indigenous priorities such as funerals and ceremonies. If one is unable to attend, for whatever reason, a proxy can usually be appointed. Attending regular meetings in regional towns and cities also caters to patterns of mobility, suiting the mix of responsibilities that individuals have to both families and localities.

Sitting fees of $\$ 500$ per day for some of these committees makes this permanent part-time range of commitments to various organisations sustainable for participants (although presumably each person has to manage potentially complex tax implications). Some Gumala members have argued that committee memberships can be understood as part of a 'mining welfare economy' that tempts individuals to remain available at the expense of gaining full-time employment. Other permanent part-time work also includes heritage surveys and the monitoring of infrastructure works: the expansion for iron ore extraction requires almost on-going survey work. In relation to Rio Tinto Iron Ore (RTIO) operations, $^{18}$ in 2006 alone in the Pilbara there were 2578 Aboriginal consultant days over 96 surveys, with further expansion expected in the following years (RTIO 2006: 32).

\section{Case 2: Lola Young}

Lola Young, aged in her 60s, lives in Tom Price. Young founded Wakuthuni, probably the first homeland in the Hamersley ranges, in 1990. An excision was negotiated with the Rocklea pastoral lease owners at the time with the assistance of the Aboriginal and Torres Strait Islander Commission (ATSIC); the lease is currently owned by RTIO. Young was one of the first members of Gumala and during 2004 was also a member of the Innawonga working group. Last year her biography was published with the assistance of Pilbara Iron (part of RTIO) (Young 2007).

As a knowledgeable Innawonga elder, Young has a high regard for the cultural value of land and maintaining attachment to it. When referring to the best methods for teaching children she has stated that 'every long weekend we need to get and teach them. If we teach them from outside of our land we get no strong inside feeling from them. You can feel it really strong when you are talking from your own land' (in Olive 1997: 99). Young has been involved with establishing two local businesses which clearly speak to this priority of cultural maintenance: Wanu Wanu and Ngumee-Ngu. The Wanu Wanu Aboriginal Corporation was established in 1997 with support from Hamerlsey Iron's (now Pilbara Iron) Aboriginal Training and Liaison Unit as a cross-cultural training business: Hamerlsey Iron employees could stay overnight in the Wakuthuni homeland as part of a suite of cultural awareness training. It was to extend to cultural and eco-tourism, but was de-registered in 2004. At the time, there was discussion

\footnotetext{
18 The RTIO operations - through Pilbara Iron — operates seven mines (including Yandicoogina) and associated infrastructure.
} 
about linking the proposed cultural and eco-tourism project in the neighboring Karijini National Park (that Gumala was planning on supporting) to Young's Wakuthuni walking tour.

The Ngumee-Ngu Aboriginal Corporation (the name of which derives from Young's 'bush name' - Ngamingu) was established in 2002, with the support of Gumala (Young 2007: 84). The objects of this corporation are listed as: 'to become self sufficient; to care for the country, the corporation and the people; to build homes within the homeland and to provide economic; social and cultural services to the community' (Office of the Registrar of Indigenous Corporations 2008). Young's biography features local knowledge about flora and its medicinal qualities, and the business includes the manufacture and sale of bush medicines based on this knowledge. The products have been sold at the annual Mount Nameless festival in Tom Price. These businesses are concerned with social and cultural cohesion and maintenance, rather than being driven principally by financial motives - although that is an aspect. Likewise, inter-generational transfer of knowledge is cited by Young as important - she works with her grandchildren on the production of the bush medicines (Young 2007: 83). The biography contains a CD of six songs performed by Young; songs learnt from her parents and from the spirits of her country (Young 2007: 160).

\section{Case 3: ID}

ID is a young to middle aged man who resided on his family homeland in the Tom Price region during 2003 and 2004. At that time he was the Secretary of the Gumala Committee, the Secretary of the GEPL Board, a member of the Innawonga Working Group, and a committee member of the Pilbara Fund (a program sponsored by the Pilbara Development Commission in Western Australia). ${ }^{19} \mathrm{He}$ had early involvement as an activist against the Rio Tinto Marandoo mine development into the Karijini National Park ${ }^{20}$ and was part of the early push toward developing cultural and eco-tourism in the Park. To this end ID was actively involved in establishing the Karijini Aboriginal Corporation in 1991 to facilitate a local Indigenous tourism operation in the Park. The first object of this Corporation was listed as, 'to support the social development of its members in all ways', followed by 'to help bring about the self-support of

\footnotetext{
19 'The Premier announced the \$20 million Pilbara Fund on 26 July 2004 to accelerate investment in the community and Government infrastructure throughout the Pilbara, particularly in the areas of health, education, recreation, culture and Government housing. The primary objective of the Pilbara Fund is to add to the welfare of all people of the Pilbara and to make the region a better place to live and work. It is intended that the Fund will facilitate the social and economic development of the Pilbara through funding projects that will enhance the long term sustainable future of the region' (Pilbara Development Commission 2008).

${ }^{20}$ For detail about this dispute see 'On the fast track to a dispute over Marandoo', M. Steketee, Sydney Morning Herald, 5 November 1991, p. 10; 'Showdown at Marandoo', M. Stevens, Business Review Weekly, 6 December 1991, p. 76.
} 
its members by the development of economic projects and industries' (Office of the Registrar of Indigenous Corporations 1990).

The Karijini Aboriginal Corporation was de-registered in 2004. However, these ideals have flowed into the development (by Gumala's business arm, GEPL) of the Karijini eco-tourism enterprise outlined above. As a GEPL Board member, ID was active in ensuring that tourist infrastructure be developed and formal arrangements be finalised for the camp grounds all under Indigenous control. As he noted himself, '... as a valuable tourist industry ... we can show off the Aboriginal culture with the aim of preservation and protection' (in Olive 1997: 205). Land related enterprises have been a signature of ID's business pursuits. In 2004, his small business sold up to 300-400 kangaroo tails a month. Under the YLUA, Rocklea Pastoral Lease (owned by RTIO) was to be returned to Gumala members. This 'handover' had not occurred in 2004, and I am uncertain as to the current situation. Nevertheless, given the early Indigenous engagement with pastoralism in this region there is a certain romance in returning to this era of stock work, now dramatically overshadowed by the mining industry, which now owns the majority of Pastoral leases in the Pilbara region. Indeed, most Indigenous people under the age of 50 would not have been exposed to the culture of station life (see Holcombe 2006: 81). ${ }^{21}$

ID developed a business proposal to utilise a herd of cattle already marked for slaughter (known as 'killer' cattle) for a local meat supply, requiring associated yards and fencing between two of the homelands near Tom Price. This project was not necessarily intended to make a profit and was reliant on the Community Development Employment Program (CDEP) for part time wages. ID indicated at that time that the project was not well received by Gumala. It would seem the proposed business had potential to grow, would assist in training young men for stock work, and offer a steady supply of meat to community residents with limited resources. This sort of enterprise is driven by a desire to return to the land, and to develop an alternative informal or domestic economy.

ID could be described as a political and cultural entrepreneur: as a strong supporter of a unified Gumala he was closely involved in the injunction against Gumala opposing GIPL's liquidation. As ID has noted, 'I have always been a fierce supporter of land rights ever since I knew what land right's was about (in Olive 1997: 204).

At the time of the field research, the three individuals above had chosen not to be involved with the IBN Corporation, even though there were clear financial incentives to do so. This Corporation covers the BHP Billiton mine (known as 'Area $\mathrm{C}^{\prime}$ ) which is an immediate neighbor to the RTIO Yandi mine. Without

${ }^{21}$ When compulsory schooling for Indigenous children was introduced in Western Australia in the late 1960s and early 1970s there was a major relocation of Indigenous workers in the pastoral industry to the towns (see Holcombe 2006: 81). 
wishing to unduly idealise the reality, this speaks to the deeper issue of group identity and the fault lines within which the regional polity is constructed. The membership rights of these three individuals to the IBN Corporation would be unquestioned and immediate, given their relationship to the native title groups through which the IBN Corporation is constituted - the Innawonga, Banyjima, and Niapali. ${ }^{22}$ However, a brief consideration of the way in which the IBN Corporation was established may explain their decisions.

When the LUA was being negotiated for the Area C mine, Gumala was well established and there was an expectation by many Gumala members (based on my interviews conducted in 2003-04) that Gumala would be the organisation that would negotiate the Agreement, which would aid its growth as a regional Indigenous organisation. Certainly there was, theoretically, 100 per cent overlap in membership of the two Agreement groups.

The concept of an overarching organisation that centralises, and thus standardises, negotiations was in some ways a forerunner to the Central Negotiating Committee that has now become the Marnda Mia Central Negotiating Committee (see earlier footnote). However, the inaugural Chairman of Gumala left when his position was not renewed, and he pursued the role of CEO of the new IBN Corporation. The significant contestation between the two organisations indicates the competition for the hearts and minds of the membership, as well as competition for Indigenous workers - both organisations have Indigenous contracting services (Gumala runs Gumala Contracting and IBN Corporation runs Indigenous Mining Services) that compete for staff.

The decisions of the three individuals discussed above are not principally motivated by financial gain; rather, their agendas articulate closely to an entrepreneurial paradigm that is underwritten by cultural and political values. As ID has stated, 'I am a strong believer in Aboriginal culture. What a lot of people don't realise is that Aboriginal culture is moving fast and adapting' (in Olive 1997: 203). These three short biographies, and indeed this quote, seemed to me to typify the types and levels of engagement that members of Gumala have with the Agreement. That is of those individuals, who choose to engage, maintaining autonomy in a manner that resonates with an Aboriginal agenda remains a significant prerogative.

\section{Case 4: SC}

The first Chairman of Gumala, SC is a more mainstream or classic entrepreneur. SC trained as a boiler maker and had worked for BHP Billiton for nine years by the time he became Gumala Chair. When he was not reappointed Gumala Chair for a second term, he developed the IBN (Innawonga, Banyjima, and Niapali)

\footnotetext{
${ }^{22}$ The IBN Corporation was an outcome of a Land Use Agreement (LUA) with BHP Billiton, as Gumala was with RTIO.
} 
Corporation to manage the Agreement for the neighboring BHP Billiton mine. ${ }^{23}$ This dynamic fissure and fusion of organisations, illustrated in the de-registration of several of the corporations discussed above, is a backdrop to the pattern of leadership. New organisations are established as existing ones cease to serve as the vehicle to progress the founder's aims and ideologies. As I have noted elsewhere, the negotiation of the YLUA was described as 'learning curve' for SC (Holcombe 2004a: 12). When an opportunity arose to develop another organisation, it was taken and the IBN Corporation was developed.

The structure of this Corporation differed significantly to that of Gumala and it is clear that the inaugural CEO transferred some lessons from his experience with the YLUA structures. Like the YLUA, two Trust funds were established under the IBN Corporation. However, unlike the Yandi Trusts, one of the IBN Corporation Trusts, the Financial Assistance Trust, did allow cash payments to members, as it was designated as non-charitable. As noted above, the issue of cash payments was significant for some Gumala members (see also Holcombe 2004a: 12-13).

Another significant difference in the IBN Corporation structure was the incorporation of four discrete bodies representing the language groups of the native title claim. ${ }^{24}$ Each group has their own administrative support and funding stream. With parallels to the issue of cash, the independence of each language group has been an ongoing source of tension for some groups within Gumala. The 2002 Review found that amongst each language group some individuals sought to devolve the current structure to language group corporations. ${ }^{25}$ However, agreement could not be reached so no action was taken. Some of this dissatisfaction lay behind the Gumala attempt to liquidate GIPL in 2007, discussed above.

A third significant difference between Gumala and the more recent IBN Corporation was the centralised authority structure that was developed by SC, as the inaugural CEO. Instead of two bodies - one that manages the Trusts (GIPL) and another operating arm (Gumala) - the IBN Corporation is structured so the CEO and the Board of Directors have oversight over both the IBN Corporation as Trustee and the operating arm (the contracting business Indigenous Mining Services). There is no separation of powers between the advisory body and the decision making body. This has been a critical issue for the IBN Corporation and member concerns about accountability and transparency.

\footnotetext{
${ }^{23}$ Note these language spellings are those used by the Corporation.

24 These are the Banyjima, Niapali, Miluranpa Banyjima and the Minadhu Innawonga groups- the two different Banyjima groups are also known as the Top End and Bottom End Bayjima groups. Note that these are the spellings used by the IBN Corporation.

25 However, there was also awareness amongst members of the significant cost implications of this administrative duplication.
} 
The four individuals in the case studies briefly discussed here are not necessarily doing anything extra-ordinary. Rather, within the limitations imposed they are negotiating their needs and in some cases pushing the boundaries.

\section{Conclusion}

Focusing on the issue of entrepreneurialism brings the tension between collective or communal rights and the rights of the individual into stark relief, although this chapter has not explored this tension in Aboriginal political process. Reconciling these apparently opposing Aboriginal values and practices is a key challenge in utilising the mainstream opportunities that the agreements offer (see Martin 1995, 2001). Mining agreements could be about offering choice and acknowledging the diversity of expectation within the Aboriginal stakeholder group, rather than operating as an experiment in social engineering. In the context of the LUAs discussed here, Indigenous entrepreneurialism is not just about engaging in the 'real economy', but also about enabling and encouraging individuals in all their heterogeneity to pursue a diverse economy. As an Aboriginal 'beneficiary' of the YLUA, Keith Lethbridge, suggested 'company structures ... [should not only] be to generate money' (Ethical Investor 2004: 33), and it may be added, not just to be directly supportive of the mining industry (see Scambary 2007, Chapter 8).

The 2002 Review into GIPL and the Trusts showed that where Aboriginal businesses are supported, they have had to be low risk and show a direct 'community benefit' (Hoffmeister 2002). Such businesses tend to be in industries that service the mine economy (see Hamersley Iron 2000). Rio Tinto's Aboriginal Training and Liaison Unit provides examples of the 'diversity and scope of business opportunities that are made possible by the Hamersley program', all are supportive of the industry. Two businesses - Wanu Wanu (discussed above) and Ngurra Wangkamagayi - run cross-cultural training courses to Hamersley Iron (now Pilbara Iron) and other companies; Ieramugadu gardening services provide contracting maintenance to Hamersley's port operations in Dampier; GEPL which operate a contracting arm (earth moving); and Gumala Eurest which operates camp accommodation and associated services.

Although clearly this is where most business opportunity exists in this region, such mainstream 'opportunity' is only taken up by 30 per cent of Indigenous adults (Taylor and Scambary 2005: 28). This suggests that looking beyond the life of the mining industry is a fanciful exercise when the pressing issue now is 'how can more Aboriginal people benefit from an LUA in terms that suit them rather than the industry?' As indicated above, these terms may be less driven by economic imperatives, than by cultural and political ones. Some realism is needed here in regard to diversifying the range of benefits that can be gained from LUAs, as it seems that the majority of those imputed to be 'beneficiaries' 
in fact benefit very little, if at all, unless they are directly employed by the Company or sit on the range of committees to undertake the process work.

While an important component of LUAs is to enable engagement with the mainstream economy through employment and training programs, choice should not be limited to this. Nevertheless, such mainstream opportunities need to be more inclusive of the disadvantaged and disenfranchised. More of the agreement capital could be allocated to building diverse forms of capital-human, social and cultural - to encourage entrepreneurialism in its many forms. The issue of whether business development proposals are specifically driven by the market should not be the only consideration in approving proposals, and nor should the size of the benefit group or community. Importantly, establishing a business development assistance scheme emerged as a means to enable a greater range of individuals, not only those that are business ready, to access a greater range of opportunity. Because the success of an individual is not an isolated achievement, the provision of scholarships to schools of the parents' choice, for instance, is a crucial element of this. It seems that the Rio Tinto WA Future Fund with the Graham (Polly) Farmer Foundation, and Gumala's new program, offers some scope here.

Limitations on choice create social pressures and fissures which highlight contestation over value and need, and Aboriginal notions of success. To capture these values, a broader consideration of 'opportunity' needs to be canvassed. This concept of opportunity, perhaps like 'capacity building', is currently based on channeling Aboriginal interests toward engagement with the mainstream and formal economies, primarily through the uptake of employment in the mine economy. When individuals are targeted by agreement programs, it tends to be in terms of specific training for skills appropriate for employment in the mining sector, and aiming at full-time employment. Engaging with this employment regime or meeting the guidelines for businesses funded under the trust structures is premised on 'opportunity', which refers to the opportunity to change - that is, to change value systems, if one is not already 'business ready' for instance (Holcombe 2006).

This issue of what might constitute Indigenous entrepreneurialism is perhaps nascent in remote Australia, as is the notion of community economies in these regions. Nonetheless, it is clear that an emergent hybrid economy is evolving in the mine hinterland region of the Pilbara. By leveraging the right to negotiate under the native title act and striking land use agreements, individuals are less focused on harvesting game (the customary economy) and more driven to harvesting heritage, through site clearances for mine works, and the development of homelands. While not every Gumala member seeks to reside on a homeland, or indeed has the customary right to establish one, neither do all Gumala members chose to, or are enabled to, work in the mining industry. Getting the balance 
right in the YLUA between catering for the range of expectations of outcomes is of course unique to it, as it is to other agreements. The purpose of this chapter has been to re-direct or refocus attention onto individuals and the ways in which they are able to articulate with the Agreement through the transformation of economic capital into social, cultural and political capital. The development of the Marnda Mia Central Negotiating Committee is a powerful example of the Agreement acting as one lever, of several, to build political capital. Likewise, local economies which revolve around cultural and eco-tourism, the manufacture of bush products and so on, also deserve space and should not be overlooked, even in the context of a regional mining boom. I return to an earlier quote: 'if the money is not being spent, it is not doing good'. This chapter has hopefully opened up the field of discussion in this space about what 'good' might mean as it is applied to a remote nascent entrepreneurialism. 